\title{
Synthesis of akageneite (beta-FeOOH)/reduced graphene oxide nanocomposites for oxidative decomposition of 2-chlorophenol by Fenton-like reaction
}

\author{
Feng Xiao ${ }^{\mathrm{a}, *}$, Wentao $\mathrm{Li}^{\mathrm{a}}$, Liping Fang ${ }^{\mathrm{b}, *}$, Dongsheng Wang ${ }^{\mathrm{a}}$ \\ a Key Laboratory of Drinking Water Science and Technology, Research Center for Eco-Environmental Sciences, Chinese Academy of Sciences, No. 18, \\ Shuangqing Road, Haidian District, Beijing 100085, China \\ ${ }^{\mathrm{b}}$ Faculty of Material Science and Chemistry, China University of Geosciences, No. 388, Lumo Road, Wuhan 430074, China
}

\section{H I G H L I G H T S}

- $\mathrm{Ak} / \mathrm{rGO}$ was successfully prepared by co-precipitating and reduction processes.

- $\mathrm{Fe}-\mathrm{O}-\mathrm{C}$ band inhabited the reduction of graphene oxide.

- Degradation rate of 2-chlorophenol for $\mathrm{Ak} / \mathrm{rGO}$ increased 2-5 times than that for Ak.

- Higher removal rate is due to the synergy of catalysis and adsorption of $\mathrm{Ak} / \mathrm{rGO}$.

\section{A R T I C L E I N F O}

\section{Article history:}

Received 17 November 2015

Received in revised form 6 January 2016

Accepted 7 January 2016

Available online 11 January 2016

\section{Keywords:}

Beta-FeOOH

Fenton-like reaction

Heterogeneous degradation

RGO

2-Chlorophenol

\section{G R A P H I C A L A B S T R A C T}

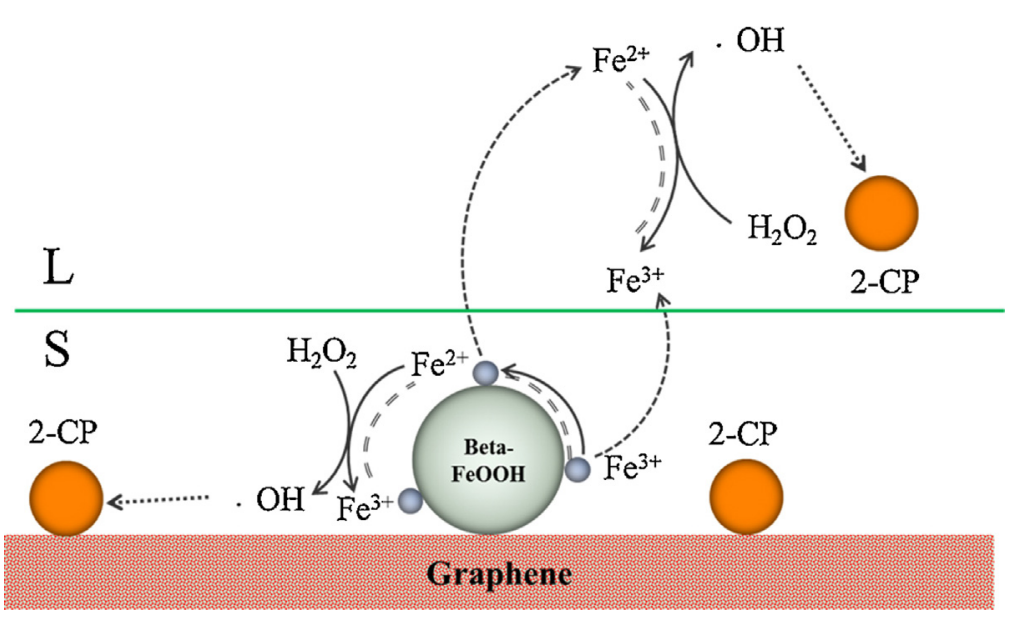

\begin{abstract}
A B S T R A C T
In this work, the composite of reduced graphene oxide and akageneite $(\mathrm{Ak} / \mathrm{rGO})$ was synthesised by co-precipitating and reduction processes. The morphological and structural features of the synthesized composites (Ak/rGO) were characterized by XRD, SEM, BET, FTIR, Zeta potential and XPS. The results revealed that (1) beta-FeOOH was successfully loaded on the reduced graphene oxide (rGO); (2) the presence of strong interfacial interactions ( $\mathrm{Fe}-\mathrm{O}-\mathrm{C}$ bonds) between $\mathrm{rGO}$ and beta-FeOOH was observed; (3) the reduction of graphene oxide may be inhabited in the formation process of beta-FeOOH, producing rGO sheets rather than $\mathrm{rGO}$ sphere. In the heterogeneous Fenton-like reaction, the degradation rate constants of 2-chlorophenol (2-CP) increased 2-5 times after the addition of rGO probably due to the $\mathrm{Fe}-\mathrm{O}-\mathrm{C}$ bond. The increase of the content of rGO could contribute to the removal of 2-CP, due to the synergy of catalysis and 2-CP adsorption towards $\mathrm{Ak} / \mathrm{rGO}$. In this study, the $\mathrm{Ak} / \mathrm{rGO}$ composite has exhibited great potential and significant prospects for environmental application.
\end{abstract}

(C) 2016 Elsevier B.V. All rights reserved.

\footnotetext{
* Corresponding authors. Fax: +86 1062849138 .

E-mail addresses: fengxiao@rcees.ac.cn, xjtuxf@gmail.com (F. Xiao), jegerfang@gmail.com (L. Fang).

http://dx.doi.org/10.1016/j.jhazmat.2016.01.011

0304-3894/@ 2016 Elsevier B.V. All rights reserved.
}

\section{Introduction}

Chlorophenols are aromatic compounds with chlorine, which are widely used in chemical industries, such as pesticides and dyes 
manufactures [1,2], as a consequence, leading to the exposure of chlorophenols in sediment of lakes and rivers [3], aerosols, and hazardous waste [4]. They are toxic and hardly biodegradable due to the stable $\mathrm{C}-\mathrm{C}$ bond in the chlorinated compounds [5]. Chlorophenols might produce disagreeable taste and odor to drinking water at certain concentrations, causing a potential negative impact on the environment, particularly they have potential carcinogenic and mutagenic activity, damaging livers' physiological processes such as apoptosis and immune response [6,7]. Moreover, they constitute a particular group of priority toxic pollutants listed by the US EPA in the Clean Water Act $[2,8]$.

Conventional methods for removing chlorophenols from wastewater include solvent extraction [9], adsorption [2,10], reverse osmosis [11], and chemical treatment processes [8,12], leading to harmful by-products, solid waste and the increase of disposal and regeneration costs. On the other hand, heterogeneous Fenton reaction, degrading organic contaminants via generating hydroxyl radicals $(\bullet \mathrm{OH})$, has many advantages over the traditional treatment methods, such as no toxic, wide reaction $\mathrm{pH}$ range and easy separation. Recently, heterogeneous Fenton reaction has received extensive attention [13-15]. Beta-FeOOH was used as Fenton-like catalyst because of a channels structure parallel to the $c$-axis [16]. Xu et al. [13] reported that methyl orange was removed by beta-FeOOH, but it was low due to weak $\mathrm{H}_{2} \mathrm{O}_{2}$-activating ability. Photo-Fenton technology was applied to enhance catalytic degradation rate. Besides Zhao et al. [14] reported that $17 \beta$-estradiol was removed completely by beta-FeOOH resin in presence of $\mathrm{H}_{2} \mathrm{O}_{2}$ under visible-light irradiation. Among these materials, graphenebased composite material has gained considerable attention due to its excellent electronic properties and high surface area as well as edge reactivity [17]. The nanoparticles loaded on the graphene are not only able to prevent the aggregation of graphene from stacking but also improve the overall catalytic performance owing to the strong synergistic interaction between both components $[18,19]$.

In this paper, the composite structures containing beta-FeOOH and reduced graphene oxide (Ak/rGO) was developed. The Ak/rGO was synthesised by co-precipitation method at low temperature $\left(100^{\circ} \mathrm{C}\right)$. To better understand their structures and functionalities, the composites were extensively characterized by using XRD, FE-SEM, FTIR, BET, Zeta potential and XPS. For the first time, the applicability of the composites in the degradation of 2-chlorophenol (2-CP) was evaluated in a heterogeneous Fenton reaction.

\section{Experimental}

\subsection{Chemicals}

Graphite powder (GP, 99.85\%-C), sodium hydroxide $(\mathrm{NaOH}$, $99 \%)$, hydrogen peroxide $\left(\mathrm{H}_{2} \mathrm{O}_{2}, 30 \%\right), 2$-chlorophenol (2-CP, $97 \%)$ and $n$-butyl alcohol $\left(\mathrm{C}_{4} \mathrm{H}_{9} \mathrm{OH}, 98 \%\right)$ were purchased from Sinopharm Chemical Reagent Co., Ltd. Ferric chloride hexahydrate $\left(\mathrm{FeCl}_{3} \cdot 6 \mathrm{H}_{2} \mathrm{O}, 97 \%\right)$ was obtained from J\&K Scientific Ltd. All the aqueous solutions were prepared by using ultrapure water (Mill-Q Biocel, $18 \mathrm{M} \Omega$ ).

\subsection{Synthesis of beta-FeOOH(Ak) nanoparticles on reduced graphene oxide (Ak/rGO)}

GO was prepared from graphite powder (GP) according to a modified Hummers method [20,21]. In detail, GP (10.0 g) was put to a mixture of concentrated $\mathrm{H}_{2} \mathrm{SO}_{4}$ and $\mathrm{H}_{3} \mathrm{PO}_{4}(9: 1,360 \mathrm{ml}: 40 \mathrm{ml})$. At the same time, $\mathrm{KMnO}_{4}(50.0 \mathrm{~g})$ was added slowly to the above mixture with stirring for $2 \mathrm{~h}$ at $35-40^{\circ} \mathrm{C}$. Then the solution was transferred to a $50^{\circ} \mathrm{C}$ water bath with a mixing for $24 \mathrm{~h}$, following by the addition of ice $(1 \mathrm{~kg})$ and $\mathrm{H}_{2} \mathrm{O}_{2}(30 \%, 3 \mathrm{ml})$. The mixture was centrifuged with $4000 \mathrm{rpm}$. Then the solid in the bottom was washed with $10 \% \mathrm{HCl}$ solution 8 times and with ethyl alcohol 8 times respectively. Finally, the collected brown powder was freeze-dried in a vacuum and stored in the ultrapure water.

GO suspension $(800 \mathrm{mg}, 160 \mathrm{ml}$ ) was sonicated in a flask for $2 \mathrm{~h}$. After the addition of the solution of $\mathrm{FeCl}_{3} \cdot 6 \mathrm{H}_{2} \mathrm{O}(0.96 \mathrm{~g}, 20 \mathrm{ml})$, the $\mathrm{pH}$ of the mixture was adjusted to 1.5 following a stirring for $4 \mathrm{~h}$. The urea was added to the above mixture until pH 1.6 with a $10 \mathrm{~min}$ stirring, heated at $100^{\circ} \mathrm{C}$ of oil bath for $4 \mathrm{~h}$. Last, the solid was centrifuged and washed with the ultrapure water till the $\mathrm{pH}$ of the supernatant was about 7.0, storing in the ultrapure water. This product was noted as Ak-20, meaning that the mass ratio of Fe to the mixture was $20 \%$.

Preparation of Ak-40, Ak-60 and Ak-80 products was the same as that of Ak-20. Ak and rGO were obtained without $\mathrm{GO}$ or $\mathrm{FeCl}_{3} \cdot 6 \mathrm{H}_{2} \mathrm{O}$ according to the method of the synthesis of Ak-20.

\subsection{Fenton-like catalytic oxidation of 2-chlorophenol}

Batch experiments were performed in plastic vessels at $298 \mathrm{~K}$. Catalysts and 2-CP were added into the reactors with $20 \mathrm{~mL}$ of final solutions with the concentrations of $1 \mathrm{~g} \mathrm{~L}^{-1}$ and $100 \mathrm{mg} \mathrm{L}^{-1}$, respectively. The $\mathrm{pH}$ of initial suspension was adjusted to 4 or 9 by $0.1 \mathrm{M} \mathrm{NaOH}$ or $\mathrm{HNO}_{3}$. The reaction was initiated by $0.1 \mathrm{M} \mathrm{H}_{2} \mathrm{O}_{2}$, and the suspension was vibrated at a speed of $200 \mathrm{r} \mathrm{min}^{-1}$. After different reaction time, the solutions were centrifuged and each supernatant was collected by filtering through $0.22 \mu \mathrm{m}$ membrane (PVDF). Finally, $n$-butanol $(20 \mu \mathrm{L})$ was added to the supernatant.

The inductively coupled plasma-atomic emission spectrometry (ICP-AES, Prodidy, Leeman Co.) was used to measure Fe concentration. The concentration of 2-CP in supernatants was determined by using Water 1525 high-performance liquid chromatography (HPLC) equipped with Water 2487 dual $\lambda$ absorbance detector. A $\mathrm{C}_{16}$ column ( $\left.4.6 \mathrm{~mm} \times 150 \mathrm{~mm}\right)$ was used as a separation column. Samples were injected into a $50 \mu \mathrm{L}$ loop and mobile phase for 2$\mathrm{CP}$ was $\mathrm{H}_{3} \mathrm{PO}_{4}(\mathrm{pH} 3.0)$ - acetonitrile $(60: 40)$ with a flow rate of $1 \mathrm{~mL} \mathrm{~min}^{-1}$. The wavelength was set at $273 \mathrm{~nm}$ for $2-\mathrm{CP}$.

\section{4. $\mathrm{H}_{2} \mathrm{O}_{2}$ degradation}

Experiments for degradation of $\mathrm{H}_{2} \mathrm{O}_{2}$ on the Ak, rGO and Ak-40 without $100 \mathrm{mg} \mathrm{L}^{-1} 2-\mathrm{CP}$ were the same with that for degradation of 2-CP. $\mathrm{H}_{2} \mathrm{O}_{2}$ concentration of the supernatant without $n$-butanol was determined immediately according to potassium titanium (IV) oxalate spectrophotometric method (U-2910, $400 \mathrm{~nm}$ ) [22].

\subsection{Characterization}

X-ray diffraction patterns were collected on an X-ray diffractometer (X'Pert PRO MPD) using $\mathrm{Cu}-\mathrm{K} \alpha$ radiation $(\lambda=1.5406 \mathrm{~A})$ operating at $40 \mathrm{mV}$ and $40 \mathrm{~mA}$, respectively. Zeta potentials and sizes of catalysts were analyzed by Zetasizer Nano size (Zetasizer 2000, Mastersize 2000, Malvern). Fourier transform infrared spectra were recorded with a FT-IR spectrophotometer (Nicolet 8700, Thermo Fisher Scientific). Raman spectra was recorded from $100 \mathrm{~cm}^{-1}$ to $2000 \mathrm{~cm}^{-1}$ on a high resolution Raman spectrometer(LabRAM HR Evolution, France) using a He-Ne laser (633 nm). Field-emission scanning electron microscope (SEM) (SU-8020, Hitachi Limited) equipped with the energy-dispersive X-ray spectrometer and Transmission electron microscopy (H-7500, Hitachi Limited) and High resolution transmission electron microscope (HRTEM) (JEM 2100F, Japan) were employed to characterize the morphology and crystalline structure of particles. The chemical composition of the catalysts was analyzed by X-ray photoelectron spectroscopy (ESCALAB 250Xi Al Ka, Thermo Fisher Scientific). 
Table 1

Chemical composition and surface area of catalysts.

\begin{tabular}{|c|c|c|c|c|c|c|c|}
\hline Samples & GO & rGO & Ak-20 & Ak-40 & Ak-60 & Ak-80 & Ak \\
\hline Actual Fe (wt/\%) & - & 0 & 23.32 & 32.87 & 42.75 & 46.61 & 54.85 \\
\hline Calculated G (wt/\%) & - & 100 & 57.48 & 40.07 & 22.06 & 15.02 & 0 \\
\hline Surface area $\left(\mathrm{m}^{2} / \mathrm{g}\right)$ & 24.83 & 402.63 & 148.93 & 159.30 & 138.37 & 83.72 & 18.65 \\
\hline Pore size $(\mathrm{nm})$ & 6.88 & 2.60 & 5.30 & 7.73 & 10.13 & 12.26 & 13.28 \\
\hline Pore volume $\left(\mathrm{cm}^{3} / \mathrm{g}\right)$ & 0.04 & 0.26 & 0.20 & 0.31 & 0.35 & 0.26 & 0.06 \\
\hline
\end{tabular}

BET surface area of the prepared catalysts was analyzed using a full automatic analyzer (ASAP2020HD88, Micromeritics Instrument Corp.).

\section{Results and discussion}

\subsection{Catalysts characterization}

\subsection{1. $X R D$}

XRD patterns of all the catalysts are shown in Fig. 1. It can be seen that the as-synthesized beta-FeOOH (Ak) was well crystallized with some feature peaks such as $\{110\}$ peak at ca. $11.8,\{200\}$ peak at ca. $16.8,\{310\}$ peak at ca. 26.8 and $\{211\}$ peak at ca. 36.2 (PDF No.34-1266). Further decrease of Fe content (Table 1) leads to the decrease of different peaks' intensity, indicating that the crystallization of beta-FeOOH could be destroyed due to the addition of rGO (Fig. 2). For instance, no obvious diffraction peaks were observed when $23.32 \%$ wt Fe was loaded onto the reduced graphene oxide (Ak-20), except a broad diffraction peak at ca. 24 of reduced graphene oxide itself, indicating the $\left\{\begin{array}{lll}0 & 0 & 2\end{array}\right\}$ plane reflection feature of grapheme [21].

\subsubsection{SEM and HRTEM}

SEM can directly identify the morphologies of catalysts. As shown in Fig. 2, rGO in the presence of beta-FeOOH was nanosheets not spherical nanoparticles. This is probably due to the aggregation of graphene oxide at $\mathrm{pH} 1.50$ with the presence of $\mathrm{Fe}^{3+}$ [23]. In addition, beta-FeOOH was nanorods of $500 \mathrm{~nm}$ in length and $50 \mathrm{~nm}$ in diameter. With the increase of Fe content, more and larger beta-FeOOH nanorods could cover on the rGO nanosheets. The morphology and structure of the $\mathrm{GO}$ and $\mathrm{Ak} / \mathrm{rGO}$ nanocomposites were also observed by HRTEM analysis. In Fig. S1, small dispersed nanorod-like particles were observed to form at the surface of rGO. With the increase of Fe content, nanoparticles grew larger and tended to be aggregated at the surface.

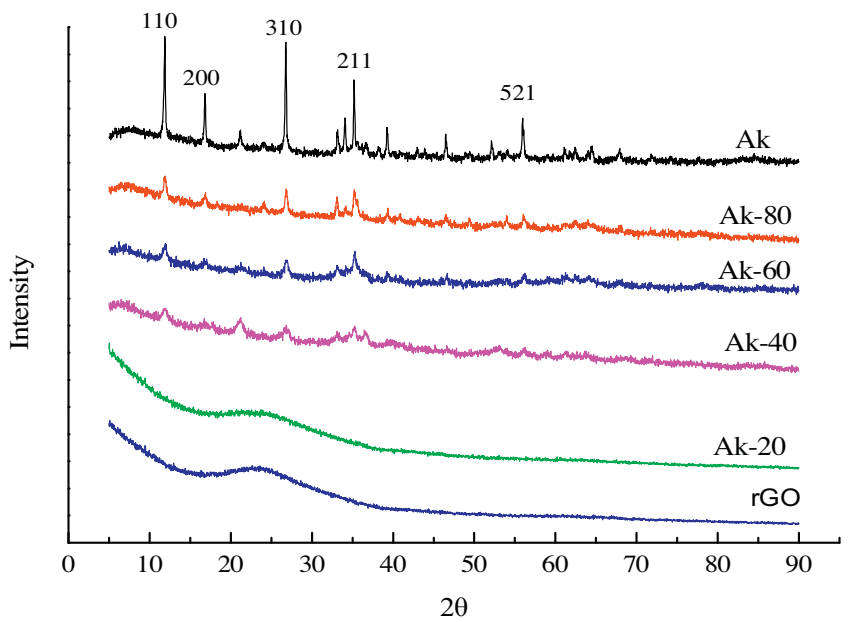

Fig. 1. XRD patterns of catalysts.

\subsubsection{Zeta potential}

To gain insight into the colloidal solution properties of catalysts, zeta potential and particle size were measured, as demonstrated in Fig. 3. The development of zeta potential as a function of $\mathrm{pH}$ reflects the different surface groups in the synthesized materials. For rGO, the surface groups include hydroxyl, epoxide, and strongly acidic carboxyl groups at the edges. rGO shows a negative zeta potential even under acidic conditions ( -20 to $-25 \mathrm{mV}$ at $\mathrm{pH} 4.02)$. As expected, rGO become to more stable as the alkalinity of the solution is increased $(\sim-50 \mathrm{mV}$ at $\mathrm{pH} 8.07)$. More interesting is that the rGO with the presence of beta-FeOOH shows a lower zeta potential although the beta-FeOOH has a higher zeta potential $(\sim 40 \mathrm{mV}$ at $\mathrm{pH}$ 7.04). For example, the zeta potential of the modified rGO with $32.87 \%$ Fe $(A k-40)$ was $\sim-30 \mathrm{mV}$ and -50 to $-55 \mathrm{mV}$ at $\mathrm{pH} 3.86$, 6.5-7.7, respectively. It is probably that beta-FeOOH nanoparticles on the rGO surfaces inhabited the reduction of part GO through masking the surface. Particle size variation is evident for $\mathrm{Ak} / \mathrm{rGO}$ materials. As shown in Fig. 3b, the particle size is observed at $10 \mu \mathrm{m}$ for rGO. For beta-FeOOH nanoparticles, there is a large sharp peak at $400 \mathrm{~nm}$ and a very small component at $100 \mathrm{~nm}$. In contrast, particle sizes of $\mathrm{Ak} / \mathrm{rGO}$ samples shift to a larger size distribution. For Ak-20 and Ak-40 samples, there is a broad peak at $300 \mu \mathrm{m}$ in the particle size. And particle sizes of Ak-60 and Ak- 80 samples stabilize at $20-30 \mu \mathrm{m}$ with a broad distribution. Particle size analysis shows that beta-FeOOH can increase the size of rGO.

\subsubsection{BET}

As depicted on Fig. 4, Nitrogen adsorption-desorption isotherms of $\mathrm{Ak} / \mathrm{rGO}$ exhibited a typical type IV with type $\mathrm{H} 3$ hysteresis loops. According to the Brunauer-Deming-Deming-Teller (BDDT) classification, it indicated that the composite is a typical mesoporous structure, which may consist of aggregates of platelike particles [24]. As shown in Table 1, the corresponding pore sizes of Ak20, Ak-40, Ak-60 and Ak-80 are $5.30 \mathrm{~nm}, 7.73 \mathrm{~nm}, 10.13 \mathrm{~nm}$ and $12.26 \mathrm{~nm}$ respectively, confirming that the composites are mainly mesoporous. The specific surface area of $\mathrm{Ak} / \mathrm{rGO}$ is larger than that of $\mathrm{Ak}$ or $\mathrm{GO}$ alone but far less than that of $\mathrm{rGO}$, indicating that beta-FeOOH could inhibit the transformation of GO to rGO

\subsubsection{FTIR and Raman}

FTIR spectroscopy was used to analyze the functional groups formed in the catalysts, as shown in Fig. 5. The FT-IR spectrum reveals the presence of $\mathrm{C}=\mathrm{O}\left(1739 \mathrm{~cm}^{-1}\right), \mathrm{C}-\mathrm{O}\left(1062 \mathrm{~cm}^{-1}\right), \mathrm{C}-\mathrm{O}-\mathrm{C}$ $\left(1229 \mathrm{~cm}^{-1}\right), \mathrm{C}-\mathrm{OH}\left(1418 \mathrm{~cm}^{-1}\right)$ in the GO samples in Fig. S2. The peak found at $1625 \mathrm{~cm}^{-1}$ is a resonance peak that can be assigned to the $\mathrm{C}-\mathrm{C}$ stretching and absorbed hydroxyl groups in the GO. With the further reduce of $\mathrm{GO}$, the new band at $1577 \mathrm{~cm}^{-1}$ appears due to $\mathrm{C}-\mathrm{C}$ stretching and oxygen functional groups almost disappear apart from $\mathrm{C}=\mathrm{O}\left(1716 \mathrm{~cm}^{-1}\right)$ and $\mathrm{C}-\mathrm{O}-\mathrm{C}\left(1222 \mathrm{~cm}^{-1}\right)$ [25]. With the increase of the beta-FeOOH content, the peaks intensity of $1716 \mathrm{~cm}^{-1}$ and $1222 \mathrm{~cm}^{-1}$ decrease. The peak of $1577 \mathrm{~cm}^{-1}$ shifts to a higher wavenumber due to the effect of $\mathrm{H}_{2} \mathrm{O}$-bending band at $1620 \mathrm{~cm}^{-1}$. The new peaks form at $1385 \mathrm{~cm}^{-1}$ and $696 \mathrm{~cm}^{-1}$. The first band may be relative to the surface Lewis acid sites, and the other one results from $\mathrm{Fe}-\mathrm{O}$ vibration $[26,27]$. For the beta-FeOOH, the bands were also observed at 3476 and $1664 \mathrm{~cm}^{-1}$, which can 

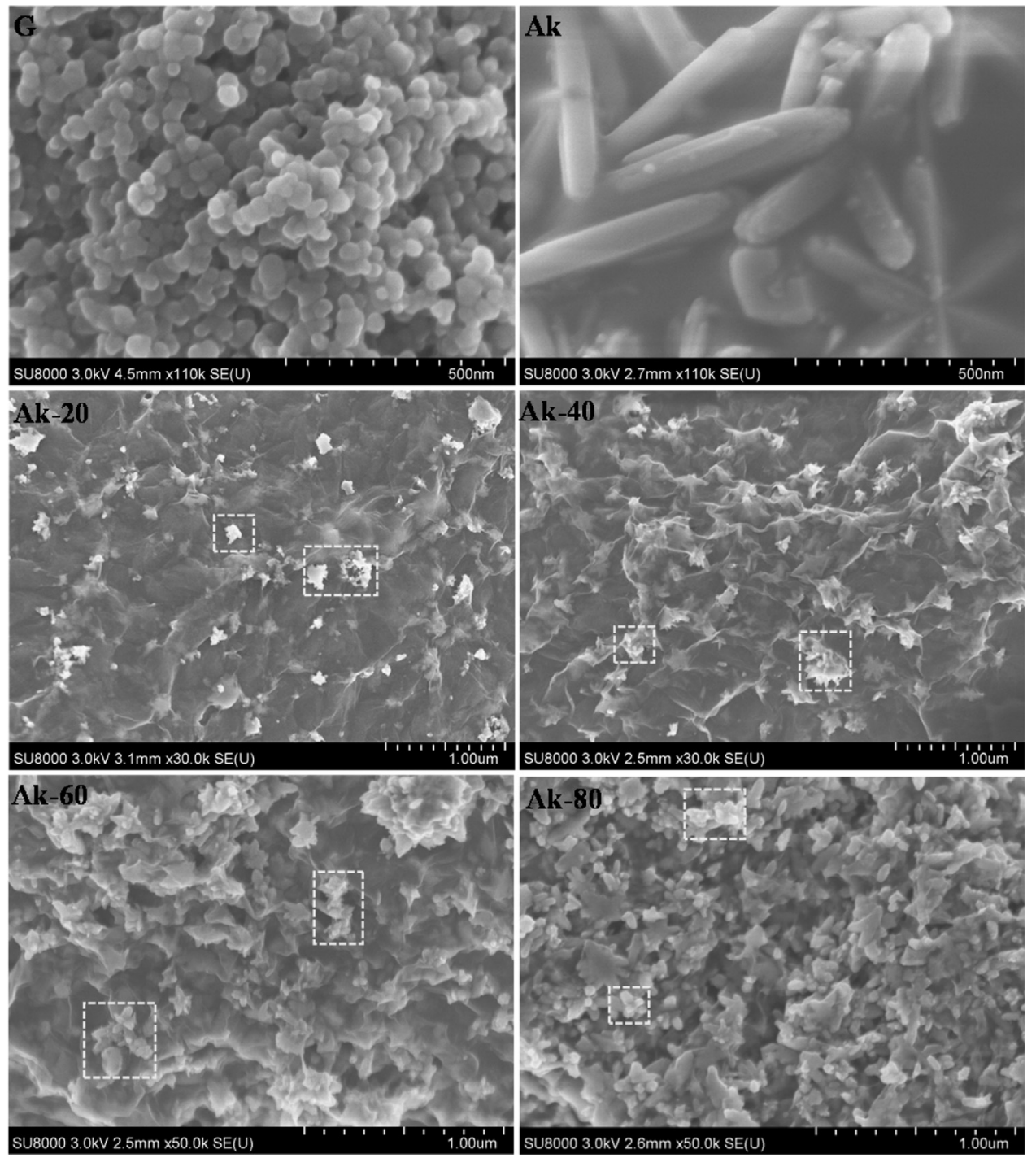

Fig. 2. SEM of catalysts: beta-FeOOH (dashed box).
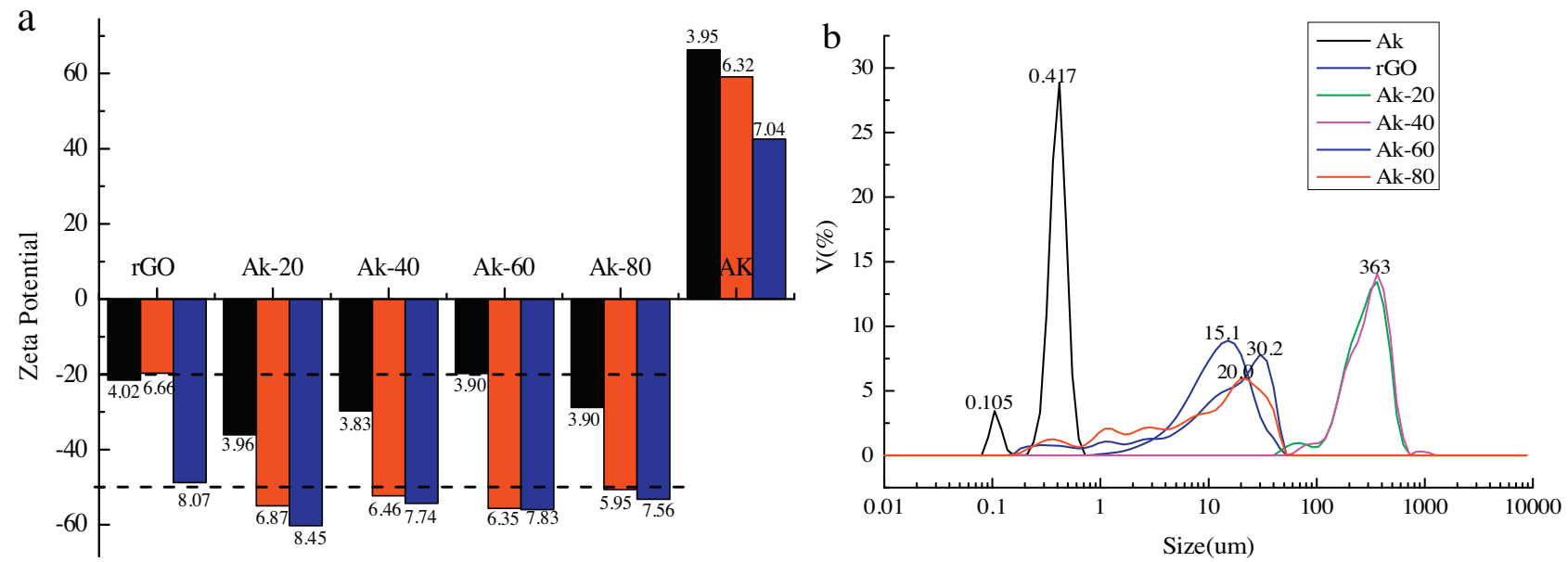

Fig. 3. Zeta potential (a) and particles size contribution (b) of catalysts. 


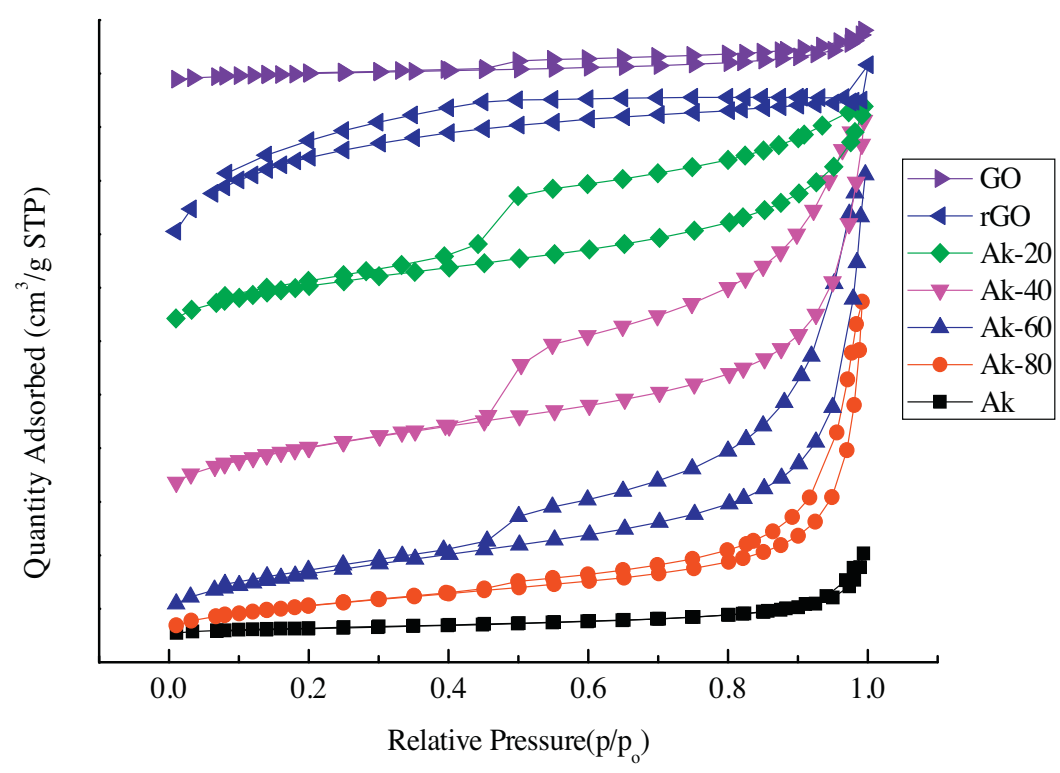

Fig. 4. $\mathrm{N}_{2}$ adsorption-desorption isotherms of catalysts.

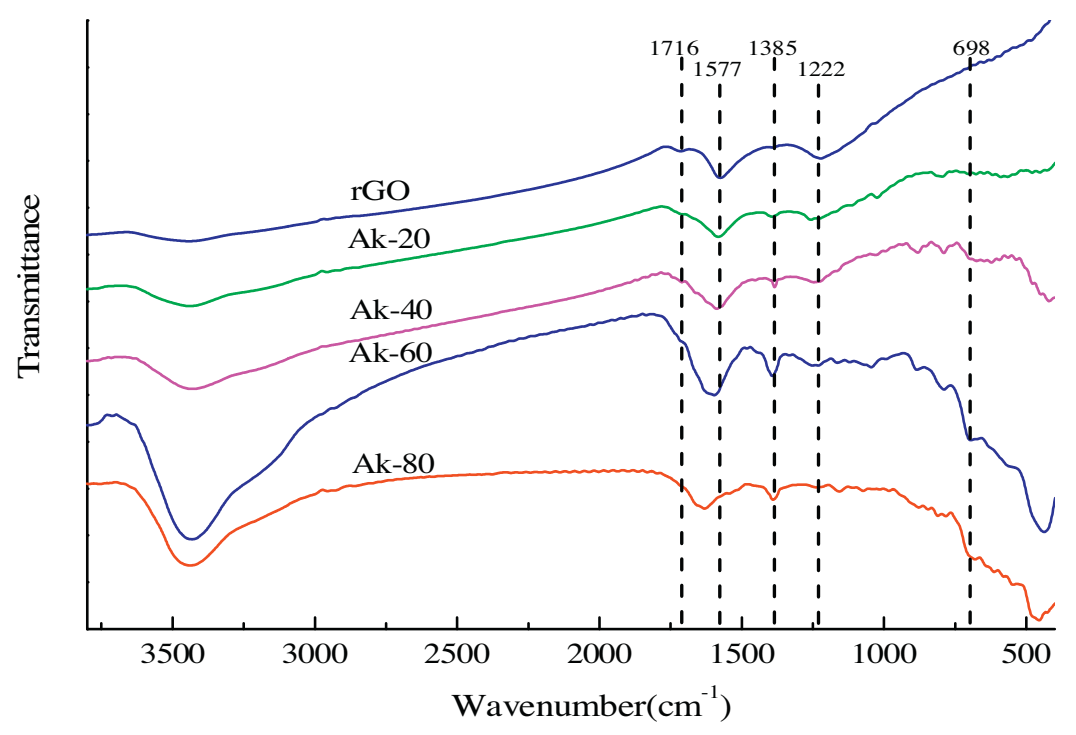

Fig. 5. FTIR spectrum of catalysts.

be assigned to the $\mathrm{OH}$-stretching band and the $\mathrm{H}_{2} \mathrm{O}$-bending band [28].

Raman spectroscopy is a powerful tool to characterize carbonaceous materials, particularly for distinguishing ordered and disordered crystal structures of carbon. Fig. 6 shows the Raman spectra of GO, rGO, Ak and Ak/rGO nanocomposites. The Raman spectrum of GO displayed a strong G at $1595 \mathrm{~cm}^{-1}$, corresponding to the first-order scattering of the E2g mode as well as a stronger D line at $1330 \mathrm{~cm}^{-1}$, indicating the reduction in size of the in-plane sp2 domains, possibly due to the extensive oxidation [29]. The Raman spectrum of the reduced GO also contains both $G$ and $D$ bands (at 1595 and $1330 \mathrm{~cm}^{-1}$, respectively). However, the intensity of $\mathrm{D}$ or $\mathrm{G}$ band intensity was higher compared to that in GO. These phenomena could be attributed to the significant decrease of the size of the in-plane sp2 domains due to oxidation and ultrasonic exfoliation [30]. In addition, the peaks at 215, 279, $394,592 \mathrm{~cm}^{-1}$ were assigned to beta-FeOOH, and peak intensity of $215,279,592 \mathrm{~cm}^{-1}$ decreased with the increase of rGO. This also indicated chemical interaction between beta-FeOOH and rGO.

\subsubsection{XPS}

The prepared catalysts were then further analyzed using XPS to verify the interaction between beta-FeOOH and rGO. As shown in Fig. S3, the wide scan spectra of catalysts showed photoelectron lines at binding energies of 284.5, 400, 529.8 and $710.8 \mathrm{eV}$ which are ascribed to $\mathrm{C} 1 \mathrm{~s}, \mathrm{~N} 1 \mathrm{~s}, \mathrm{O} 1 \mathrm{~s}$ and Fe2p, respectively. The C1s peaks, O1s peaks and Fe2p peaks of catalysts are showed in Fig. 7, the fit results of which are summarized in Table S1. High resolution XPS profiles of $\mathrm{C} 1 \mathrm{~s}, \mathrm{O} 1 \mathrm{~s}$ and $\mathrm{Fe} 2 \mathrm{p}$ exhibited asymmetric character, indicating the presences of different kinds of surface carbon, oxygen and ferric species on the catalysts. Fig. 7a shows the Fe2p spectra of Ak, Ak-20 and Ak-60. The binding energy peaks for Ak sample at 710.7 and $724.2 \mathrm{eV}$ in the high resolution Fe2p scan corresponded to $\mathrm{Fe} 2 \mathrm{p} 3 / 2$ and $\mathrm{Fe} 2 \mathrm{p} 1 / 2$, respectively. With the addition of $\mathrm{rGO}$, the Fe2p peaks shifted to the higher binding energy (i.e., $711.6 \mathrm{eV}$ and $724.8 \mathrm{eV}$ for the Fe2p3/2and Fe2p1/2 peaks of Ak-60 sample), indicating the chemical interaction between beta-FeOOH and rGO.

The C1s spectra of catalysts are exhibited in Fig. 7b. The decomposition of the $\mathrm{C} 1 \mathrm{~s}$ spectrum of catalysts consists 


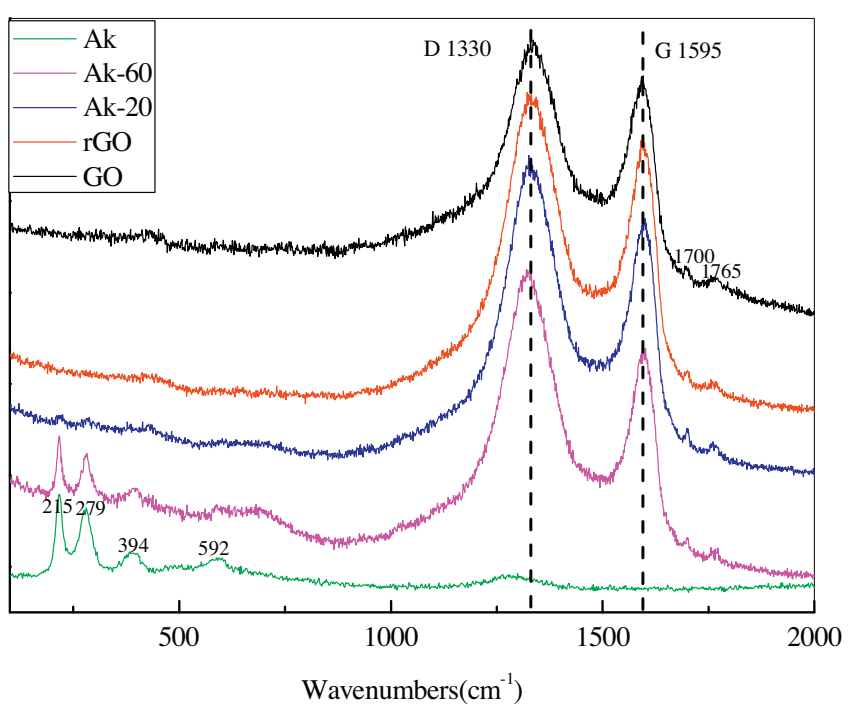

Fig. 6. Raman spectrum of catalysts.

of six components: $\mathrm{C}=\mathrm{Csp}^{2}(284.6-284.8 \mathrm{eV}), \mathrm{C}-\mathrm{Csp}^{3}$ or $\mathrm{C}-\mathrm{N}$ $(285.2-285.9 \mathrm{eV}), \mathrm{C}-\mathrm{OH}$ and or $\mathrm{C}-\mathrm{O}-\mathrm{C}(286.6-286.9 \mathrm{eV}), \mathrm{C}=\mathrm{O}$ (287.7-288.1 eV), $\mathrm{O}-\mathrm{C}=\mathrm{O}(288.6-289.0 \mathrm{eV})$ and shake-up satellite peaks (291.1-293.1 eV) due to transitions in aromatic rings or carbon in carbonate groups [31]. It is also observed that the binding energy of 285.2-285.9 eV corresponds to $\mathrm{C}-\mathrm{C}$ or $\mathrm{C}-\mathrm{N}$ peaks $[19,31]$ indicating that $\mathrm{N}$ was doped into the catalysts. Unlike the $\mathrm{C} 1 \mathrm{~s}$ sig-
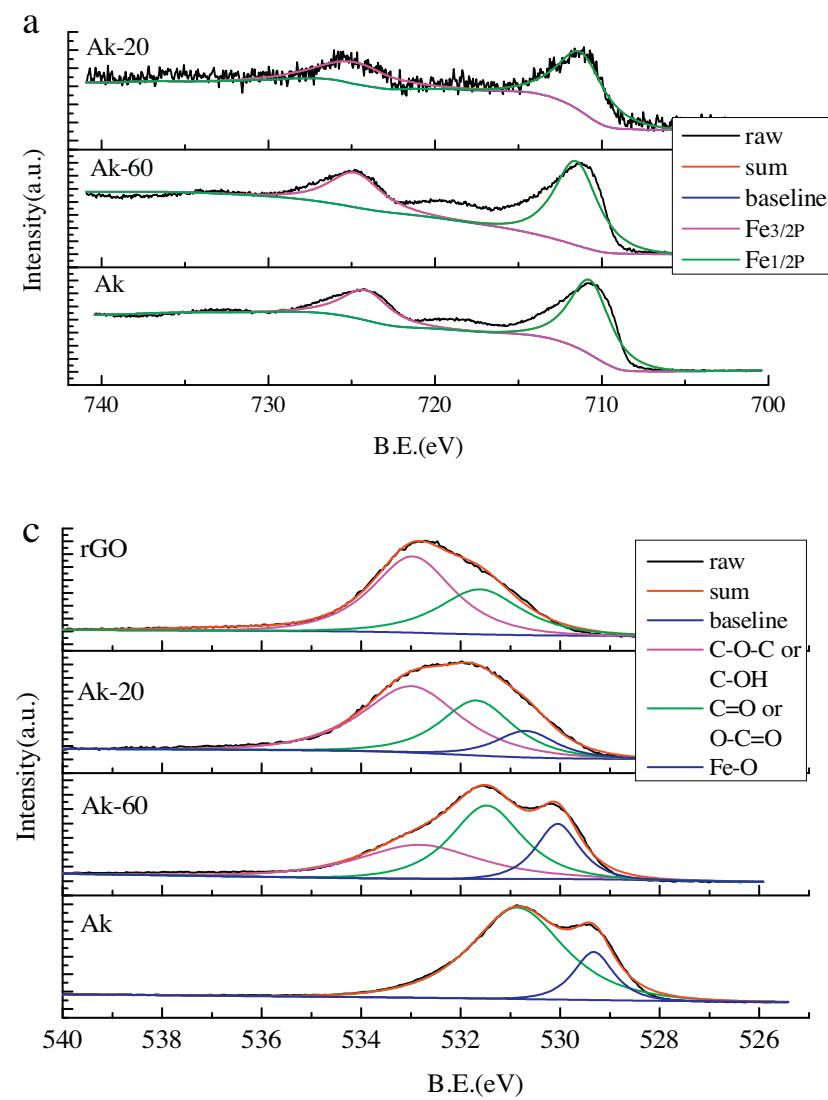

nals, the 01s peaks exhibit a difference in Fig. 7c. Further the 01s spectrum of catalysts can be well decomposed into three peaks: the oxygen that blinds to $\mathrm{Fe}(\mathrm{Fe}-\mathrm{O}(\mathrm{H}): 529.3-530.9 \mathrm{eV})$, the oxygen in carboxylate or carbonyl $(\mathrm{O}-\mathrm{C}=\mathrm{O}$ or $\mathrm{C}=\mathrm{O}$ : $531.5-531.7 \mathrm{eV})$, the oxygen in the epoxy or hydroxyl (C-O-C; $\mathrm{C}-\mathrm{OH}$ : $532.8-533 \mathrm{eV})$. It should be noticed that the peaks of $01 \mathrm{~s}$ in Ak-20, Ak-60 samples shifted to a lower binding energy of $529.3 \mathrm{eV}(\mathrm{Fe}-\mathrm{O})$ in $\mathrm{Ak}$, indicating that the new peak of $\mathrm{Fe}-\mathrm{O}-\mathrm{C}$ at the binding energy of $531.2 \mathrm{eV}$ may be formed on the surface of rGO [31]. Besides, the binding energy of $529.3 \mathrm{eV}$ and $530.9 \mathrm{eV}$ corresponds to $\mathrm{Fe}-\mathrm{O}$ and $\mathrm{Fe}-\mathrm{OH}[32]$.

\subsection{Fenton-like catalytic oxidation of 2-chlorophenol}

In order to test the catalytic performance of $\mathrm{Ak} / \mathrm{rGO}$, the Fentonlike oxidation of 2-chlorophenol was employed as a typical action. The degradation of 2-CP under different experimental conditions was evaluated. As shown in Fig. 8a, 2-CP removal efficiency by using catalysts in the presence of $100 \mathrm{mM} \mathrm{H}_{2} \mathrm{O}_{2}$ were measured at initial $\mathrm{pH} 4.0$ within $72 \mathrm{~h}$. 2-CP removal efficiency could achieve to $88 \%$ with the addition of beta-FeOOH, which demonstrated a linear relationship with time. The degradation of 2-CP was compared by using the $\mathrm{Ak} / \mathrm{rGO}$. For instance, 2-CP removal efficiency was $67 \%$ by using similar dosage of Ak-80 in $24 \mathrm{~h}$. Almost all of 2-CP was removed for Ak-20, Ak-40 and Ak-60 in $16 \mathrm{~h}$. In contrast, removal of 2-CP is decreased at initial pH 9.0 (Fig. 8b). Particularly, only 33\% 2-CP was removed for beta-FeOOH because the release iron and $\mathrm{OH}$ radical could be decreased [33]. However, Ak-20 and Ak-40 showed a little change in 2-CP removal, because of the rGO content. If the

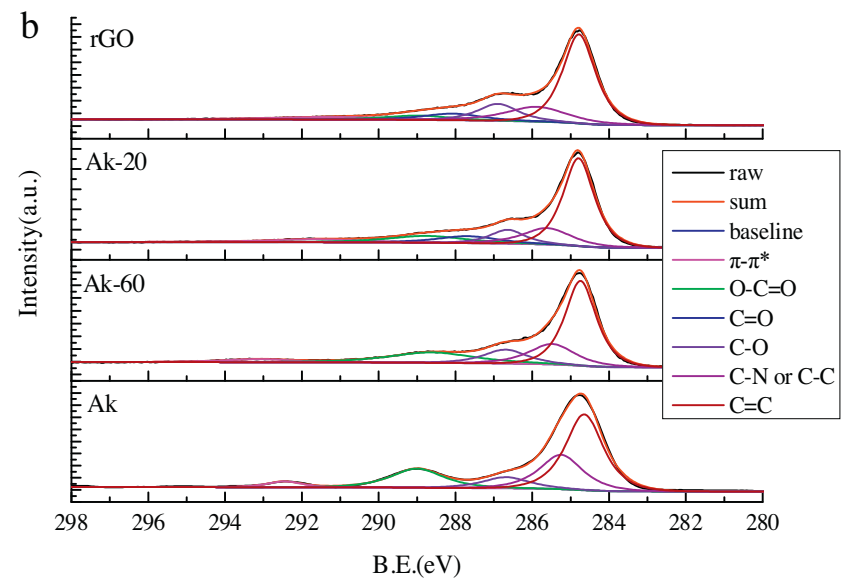

Fig. 7. XPS curve fit of Fe2p (a), C1s (b) and O1s (c) spectra. 
a

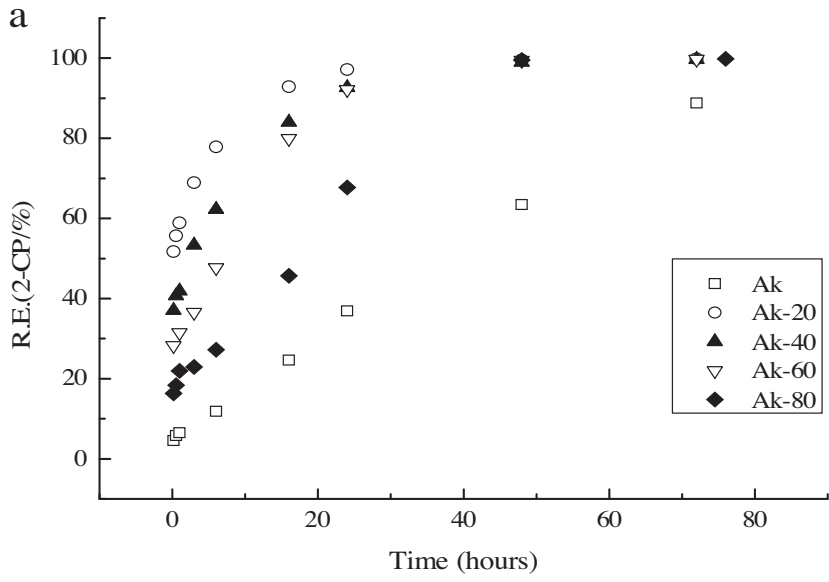

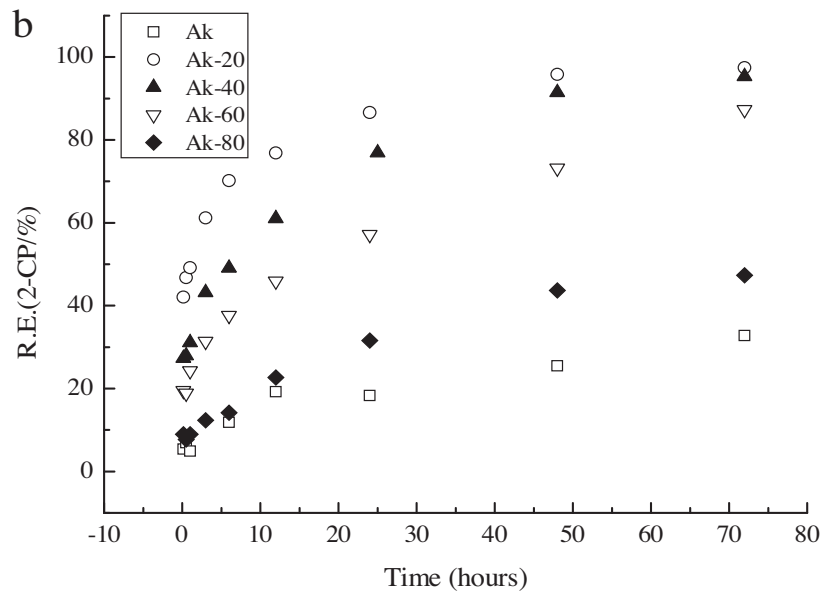

Fig. 8. Removal of 2-CP on the $\mathrm{Ak} / \mathrm{rGO}\left(1 \mathrm{~g} \mathrm{~L}^{-1}\right.$ catalyst, $\left.100 \mathrm{mg} \mathrm{L}^{-1} 2-\mathrm{CP}, 100 \mathrm{mM} \mathrm{H}_{2} \mathrm{O}_{2}\right)$ : (a) initial $\mathrm{pH} 4.0$, (b) initial $\mathrm{pH} 9.0$.
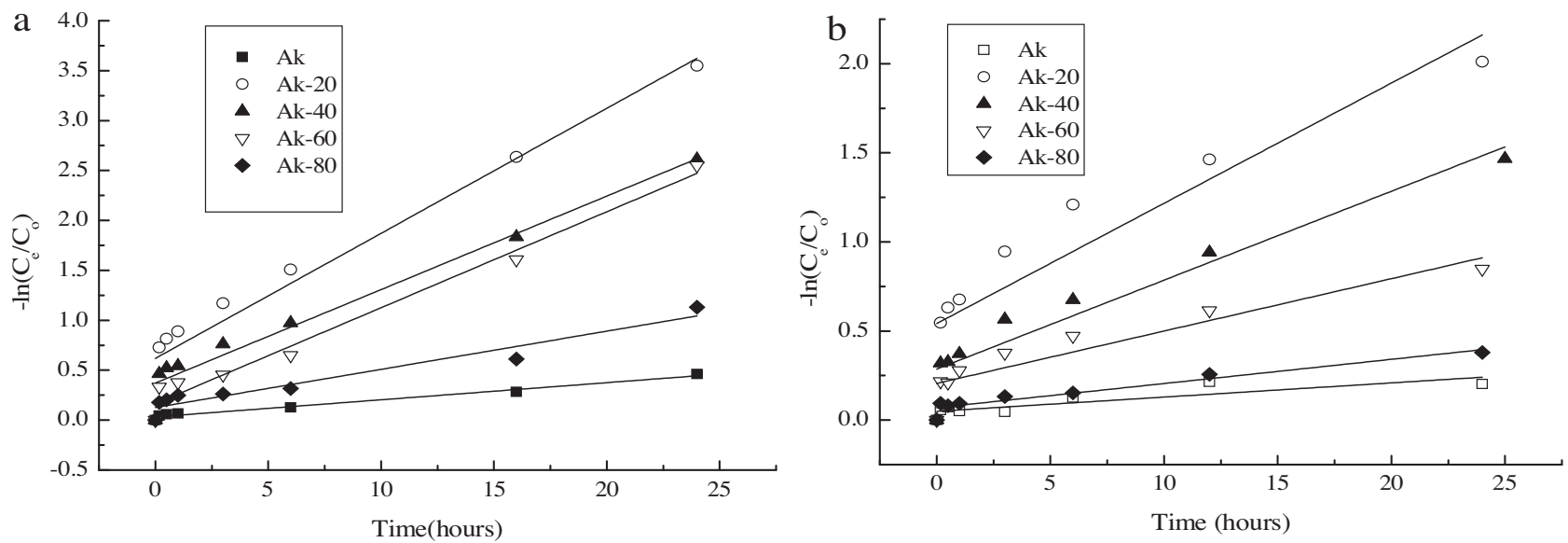

Fig. 9. Dynamic process of 2-CP on the catalysts at initial pH 4.0 (a) and $\mathrm{pH} 9.0$ (b).

dosage was the same, 2-CP removal efficiency reached almost same as $75 \%$ with $\mathrm{H}_{2} \mathrm{O}_{2}$ at initial $\mathrm{pH} 4.0$ or 9.0 . This is likely due to the adsorption, as shown in Fig. S4. This means that the rGO could help the degradation of 2-CP through adsorption and thereby improving the reaction rate.

\subsection{Mechanism analysis}

\subsubsection{Released iron concentration}

To gain insight of the Fenton-like oxidation of 2-chlorophenol, the concentrations of soluble Fe produced from the protonpromoted dissolution of beta-FeOOH were examined, which could activate the Fenton reaction $[34,35]$. According to Fig. S5, more soluble irons are from $\mathrm{Ak} / \mathrm{rGO}$ rather than beta-FeOOH at initial $\mathrm{pH} 4.0$ or 9.0. This result indicates that the presence of rGO could accelerate the Fenton reaction.

\subsubsection{Kinetic equation}

The experimental results for the degradation rate of 2-CP at initial $\mathrm{pH} 4.0$ or 9.0 were described by pseudo first order kinetics, as shown in Fig. 9. From Table S2, where the curve fit results were summarized, the $2-\mathrm{CP}$ oxidation rate at initial pH 4.0 is $2-3$ times higher than that at initial $\mathrm{pH} 9.0$. The decrease of the decomposition rate at higher $\mathrm{pH}$ was attributed to the precipitation of $\mathrm{Fe}(\mathrm{III})$ and the reduction of $\mathrm{H}_{2} \mathrm{O}_{2}$ life [36]. With the increase of rGO content, oxidation rates of 2-CP increase exponentially (i.e., oxidation rates

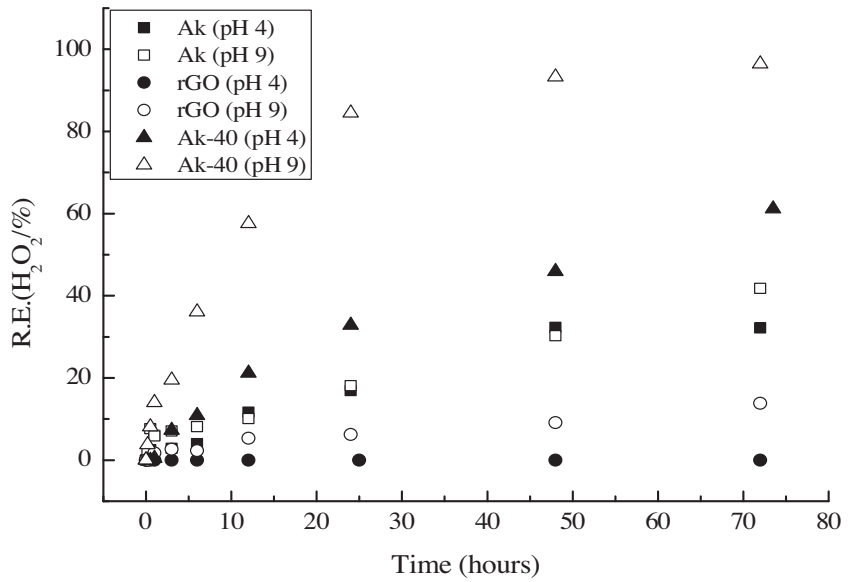

Fig. 10. Degradation of $\mathrm{H}_{2} \mathrm{O}_{2}$ onto the $\mathrm{Ak}, \mathrm{rGO}$ and $\mathrm{Ak}-40$.

of 2-CP for Ak-20 is almost 10 times than that for $\mathrm{Ak}$ ), implying that the catalytic activity was enhanced by the introduction of rGO.

\subsection{3. $\mathrm{H}_{2} \mathrm{O}_{2}$ degradation}

Degradation of $\mathrm{H}_{2} \mathrm{O}_{2}$ on the Ak, Ak-40 and rGO without 2-CP is exhibited in Fig. 10. Many researchers [33] observe that $\mathrm{OH}$ radical is proportional to $\mathrm{H}_{2} \mathrm{O}_{2}$. Compared with $\mathrm{Ak}, \mathrm{H}_{2} \mathrm{O}_{2}$ degradation on Ak-40 increased significantly whether initial pH as 4.0 or 9.0. 

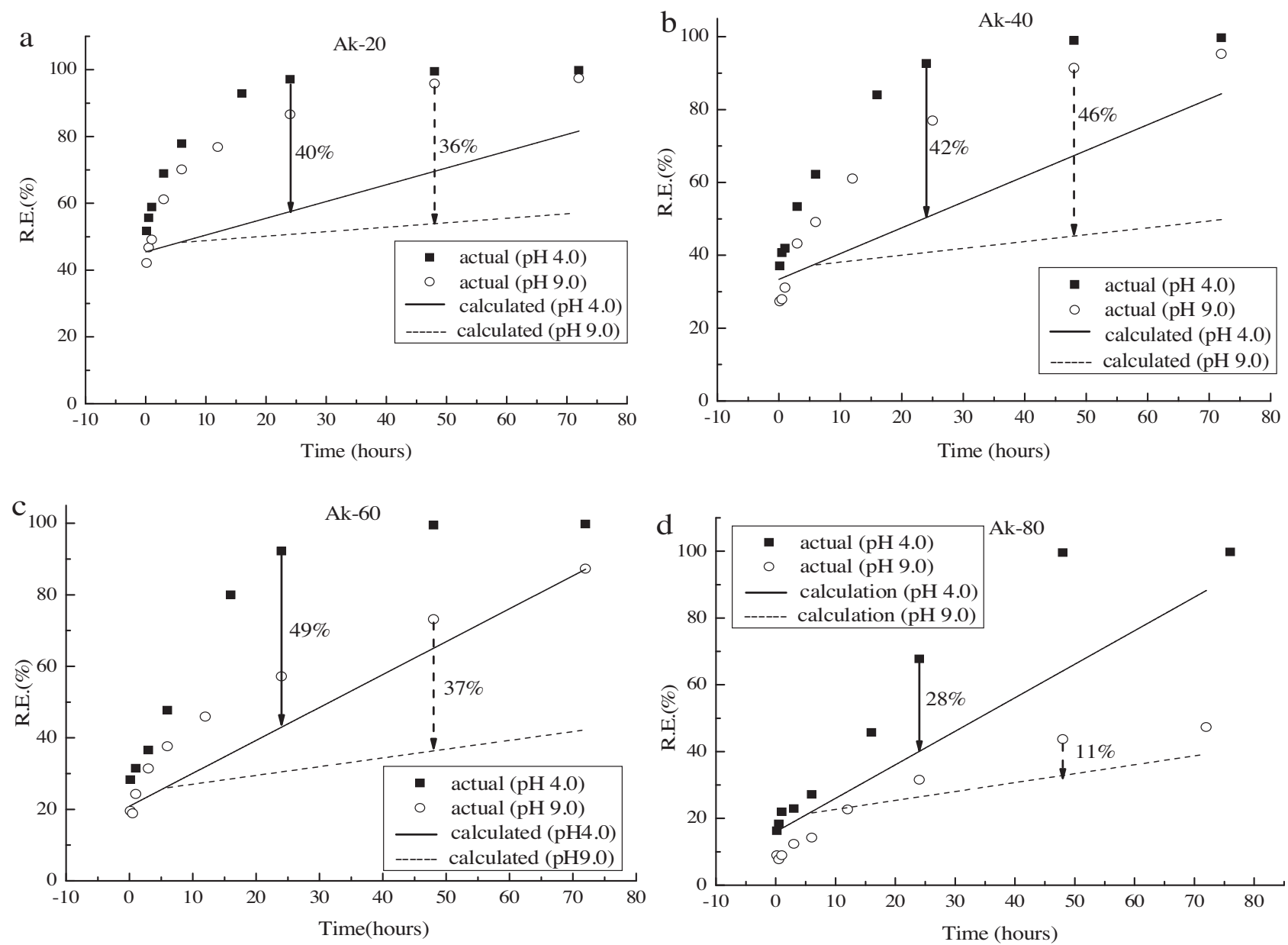

Fig. 11. 2-CP removal via Synergy of reduced graphene oxide and beta-FeOOH.

Besides, degradation of $\mathrm{H}_{2} \mathrm{O}_{2}$ onto the rGO was much lower and almost can be neglected. This indicates that certain active site on the $\mathrm{Ak} / \mathrm{rGO}$ contributes to $\mathrm{H}_{2} \mathrm{O}_{2}$ degradation, producing more $\mathrm{OH}$ radical.

\subsubsection{Synergism of rGO and beta-FeOOH}

Furthermore, the degradation of 2-CP by a physical mixture of beta-FeOOH and $\mathrm{rGO}$ in the presence of $\mathrm{H}_{2} \mathrm{O}_{2}$ was modeled, providing that (1) not interfering with the reactions between them; (2) a model parameters producing from the degradation of $2-\mathrm{CP}$ on the beta-FeOOH and rGO, respectively.

(a)R.E. $(\mathrm{rGO})=75 \% \times$ rGOcontent

(b)R.E.(A.k) $=5.56+1.18 \times \operatorname{Time}(\mathrm{h})\left(\right.$ initialpH4.0, $\left.R^{2}=0.9973\right)$

$$
\text { R.E.(A.k) }=10.33+0.31 \times \text { Time }(\text { h })\left(\text { initialpH9.0, } R^{2}\right.
$$$$
=0.9980, \text { Time }>6 h)
$$

TotalR.E $=$ R.E. $($ rGO $)+$ R.E. $($ Ak $) \times(1-$ rGOcontent $)$

In Eq. (a), rGO contents are 57.48\%, 40.07\%, 22.06\%, 15.02\% for Ak-20, Ak-40, Ak-60, Ak-80, respectively, where $75 \%$ is assumed as removal efficiency of 2-CP at initial $\mathrm{pH} 4.0$ or 9.0 due to $2-\mathrm{CP}$ removal range from $71 \%$ to $78 \%$.As shown in Fig. 11, 2-CP removal efficiency on the composite is increased significantly. For example, 2-CP removal difference between Ak-20 and corresponding

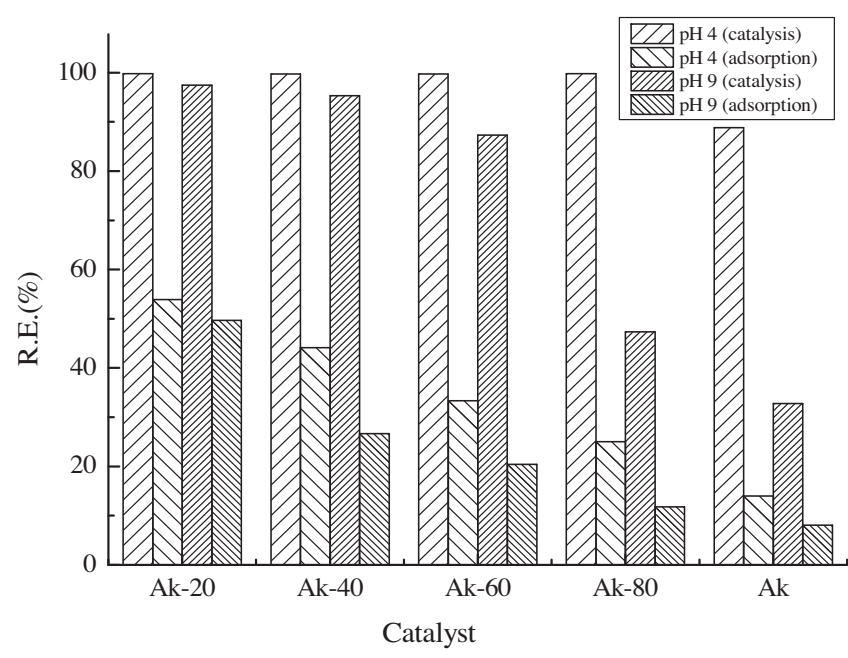

Fig. 12. Removal of $2-\mathrm{CP}$ onto the catalysts after $72 \mathrm{~h}$.

mixture rises with the increase of reaction time, reaching $40 \%$ and $36 \%$ at initial $\mathrm{pH} 4.0$ and 9.0. By comparison, the catalytic activity of $\mathrm{Ak} / \mathrm{rGO}$ composites were higher than that of mixture, suggesting that there might be a synergy effect in the composite, thereby enhancing the relative rates of mass transfer to reactive sites and chemical reaction at reactive sites. In addition, synergy of betaFeOOH and $\mathrm{rGO}$ for Ak-40, Ak-60 and Ak-80 is quite significant, as seen in Fig. 12. 
Based on the information obtained above, a possible reaction mechanism of $\mathrm{Ak} / \mathrm{rGO}$ toward the reduction of $2-\mathrm{CP}$ is proposed in Fig. S6. The mechanisms involved in the Fenton-like oxidation of organic compounds could be explained by considering both the reactions in solution and at the beta-FeOOH surface. As reported by other researchers [33,37], the first step in the heterogeneous reaction is the surface complexation of $\mathrm{H}_{2} \mathrm{O}_{2}$ to $\mathrm{Fe}$ (III) forming $\mathrm{Fe}^{\mathrm{III}} \mathrm{H}_{2} \mathrm{O}_{2}$, leading to the formation of $\bullet \mathrm{OH}$ radicals in solution (Eqs. (1)-(4)), which degrades 2-CP (Eq. (11)). In the bulk solution, dissolved iron from beta-FeOOH initiates the decomposition of $\mathrm{H}_{2} \mathrm{O}_{2}$ through a chain reaction (Eqs. (5)-(10)) to produce $\bullet \mathrm{OH}$, which degrades 2 $\mathrm{CP}$ (Eq. (11)). At the same time, adsorption has important pole in the process of 2-CP degradation.

$$
\begin{aligned}
& \equiv \mathrm{Fe}^{\mathrm{III}}+\mathrm{H}_{2} \mathrm{O}_{2} \rightarrow \equiv \mathrm{Fe}^{\mathrm{III}} \mathrm{H}_{2} \mathrm{O}_{2} \\
& \equiv \mathrm{Fe}^{\mathrm{III}} \mathrm{H}_{2} \mathrm{O}_{2} \rightarrow \equiv \mathrm{Fe}^{\mathrm{II}}+\mathrm{HO}_{2} \bullet+\mathrm{H}^{+} \\
& \equiv \mathrm{Fe}^{\mathrm{II}}+\mathrm{H}_{2} \mathrm{O}_{2} \rightarrow \equiv \mathrm{Fe}^{\mathrm{III}}+{ }^{\circ} \mathrm{OH}+\mathrm{OH}^{-} \\
& \equiv \mathrm{Fe}^{\mathrm{III}}+\mathrm{HO}_{2} \cdot \rightarrow \mathrm{Fe}^{\mathrm{II}}+\mathrm{H}^{+}+\mathrm{O}_{2} \\
& \mathrm{Fe}^{3+}+\mathrm{H}_{2} \mathrm{O}_{2} \rightarrow \mathrm{Fe}^{2+}+\mathrm{HO}_{2} \cdot \mathrm{H}^{+} \\
& \mathrm{Fe}^{2+}+\mathrm{H}_{2} \mathrm{O}_{2} \rightarrow \mathrm{Fe}^{3+}+{ }^{\circ} \mathrm{OH}+\mathrm{OH}^{-} \\
& \mathrm{Fe}^{3+}+\mathrm{HO}_{2} \cdot \rightarrow \mathrm{Fe}^{2+}+\mathrm{H}^{+}+\mathrm{O}_{2} \\
& { }^{\circ} \mathrm{OH}+\mathrm{H}_{2} \mathrm{O}_{2} \rightarrow \mathrm{H}_{2} \mathrm{O}+\mathrm{HO}_{2} \cdot \\
& \mathrm{Fe}^{2+}+\mathrm{H}^{+}+\mathrm{HO}_{2} \cdot \rightarrow \mathrm{Fe}^{3+}+\mathrm{H}_{2} \mathrm{O}_{2} \\
& \mathrm{Fe}^{2+}+{ }^{\circ} \mathrm{OH}^{3} \rightarrow \mathrm{Fe}^{3+}+\mathrm{OH}^{-}
\end{aligned}
$$

$2-\mathrm{CP}+{ }^{\circ} \mathrm{OH} \rightarrow$ Products

\section{Conclusions}

In summary, Ak/rGO composites were prepared by a facile co-precipitation method. The presence of rGO prevented the betaFeOOH NP from aggregating and enabled them to distribute uniformly on the surface of the rGO sheets, activating the reactive sites. Furthermore, Ak/rGO composites showed efficient catalytic activity for the reduction of 2-CP at acid or alkaline conditions. On the basis of iron leaching, $\mathrm{H}_{2} \mathrm{O}_{2}$ degradation and comparison of model, $\mathrm{Ak} / \mathrm{rGO}$ composites can produce more $\mathrm{OH}$ radical to enhance 2-CP degradation, implying that using graphene as a host material for catalysts to accomplish synthetic transformations has great potential and far-reaching prospects for environmental application.

\section{Acknowledgements}

We gratefully thank the National Basic Research Program from Ministry of Science and Technology (no. 2011CB933700), National Natural Science Foundation of China (no. 51378014, 51338008, 51578529, 21407131), and the support from "Engineering Research Center of Nano-Geo Materials of Ministry of Education, China University of Geosciences (Wuhan)".

\section{Appendix A. Supplementary data}

Supplementary data associated with this article can be found, in the online version, at http://dx.doi.org/10.1016/j.jhazmat.2016.01. 011.

\section{References}

[1] I. Fernández, M.E. Suárez-Ojeda, J. Pérez, J. Carrera, Aerobic biodegradation of a mixture of monosubstituted phenols in a sequencing batch reactor, J. Hazard. Mater. 260 (2013) 563-568.
[2] J. Rashid, M.A. Barakat, S.L. Pettit, J.N. Kuhn, In $\mathrm{VO}_{4} / \mathrm{TiO}_{2}$ composite for visible-light photocatalytic degradation of 2-chlorophenol in wastewater, Environ. Technol. 35 (2014) 2153-2159.

[3] M.H. Sung, C.P. Huang, In situ removal of 2-chlorophenol from unsaturated soils by ozonation, Environ. Sci. Technol. 36 (2002) 2911-2918.

[4] Y.H. Chuang, Y.M. Tzou, M.K. Wang, C.H. Liu, P.N. Chiang, Removal of 2-chlorophenol from aqueous solution by $\mathrm{Mg} / \mathrm{Al}$ layered double hydroxide (LDH) and modified LDH, Ind. Eng. Chem. Res. 47 (2008) 3813-3819.

[5] H. Roques, Chemical Water Treatment: Principles and Practice, Wiley, Wien heim, 1996.

[6] L. Gombos, J. Kardos, A. Patthy, P. Medveczky, L. Szilagyi, A.M. Csizmadia, L. Graf, Probing conformational plasticity of the activation domain of trypsin: the role of glycine hinges, Biochemistry 47 (2008) 1675-1684.

[7] Y.Q. Wang, C.Y. Tan, S.L. Zhuang, P.Z. Zhai, Y. Cui, Q.H. Zhou, H.M. Zhang, Z.H. Fei, In vitro and in silico investigations of the binding interactions between chlorophenols and trypsin, J. Hazard. Mater. 278 (2014) 55-65.

[8] N. Li, C. Descorme, M. Besson, Catalytic wet air oxidation of aqueous solution of 2-chlorophenol over Ru/zirconia catalysts, Appl. Catal. B: Environ. 71 (2007) 262-270

[9] W. Kujawski, A. Warszawski, W. Ratajczak, T. Porebski, W. Capala, I. Ostrowska, Removal of phenol from wastewater by different separation techniques, Desalination 163 (2004) 287-296.

[10] Y.J. Zhang, R.G. Mancke, M. Sabelfeld, S.U. Geißen, Adsorption of trichlorophenol on zeolite and adsorbent regeneration with ozone, J. Hazard. Mater. 271 (2014) 178-184.

[11] V.V. Goncharuk, D.D. Kucheruk, V.M. Kochkodan, V.P. Badekha, Removal of organic substances from aqueous solutions by reagent enhanced reverse osmosis, Desalination 143 (2002) 45-51.

[12] Y.Y. Chu, W.J. Wang, M. Wang, Anodic oxidation process for the degradation of 2,4-dichlorophenol in aqueous solution and the enhancement of biodegradability, J. Hazard. Mater. 180 (2010) 247-252.

[13] Z.H. Xu, M. Zhang. J.Y. Wu, J.R. Liang, L.X. Zhou, B. Lu, Visible light-degradation of azo dye methyl orange using $\mathrm{TiO}_{2} / \beta-\mathrm{FeOOH}$ as a heterogeneous photo-Fenton-like catalyst, Water Sci. Technol. 68 (2013) 2178.

[14] Y.P. Zhao, J.Y. Hu, H.B. Chen, Elimination of estrogen and its estrogenicity by heterogeneous photo-Fenton catalyst $\beta-\mathrm{FeOOH} / \mathrm{resin}, \mathrm{J}$. Photochem. Photobiol. A 212 (2010) 94-100.

[15] R. Mecozzi, L.D. Palma, D. Pilone, L. Cerboni, Use of EAF dust as heterogeneous catalyst in Fenton oxidation of PCP contaminated wastewaters, J. Hazard. Mater. 137 (2006) 886-892.

[16] Z.Y. Yuan, T.Z. Ren, B.L. Su, Surfactant mediated nanoparticle assembly of catalytic mesoporous crystalline iron oxide materials, Catal. Today 93 (2004) $743-750$

[17] W. Fan, W. Gao, C. Zhang, W.W. Tjiu, J.S. Pan, T.X. Liu, Hybridization of graphene sheets and carbon-coated $\mathrm{Fe}_{3} \mathrm{O}_{4}$ nanoparticles as a synergistic adsorbent of organic dyes, J. Mater. Chem. 22 (2012) 25108-25115.

[18] T. Zeng, X.L. Zhang, Y.R. Ma, H.Y. Niu, Y.Q. Cai, A novel $\mathrm{Fe}_{3} \mathrm{O}_{4}$-graphene Au multifunctional nanocomposite: green synthesis and catalytic application, J. Mater. Chem. 22 (2012) 18658-18663.

[19] Y. Choi, H.S. Bae, E. Seo, S. Jang, K.H. Park, B.S. Kim, Hybrid gold nanoparticle-reduced graphene oxide nanosheets as active catalysts for highly efficient reduction of nitroarenes, J. Mater. Chem. 21 (2011) 15431-15436.

[20] D.C. Marcano, D.V. Kosynkin, J.M. Berlin, A. Sinitskii, Z.Z. Sun, A. Slesarev, L.B. Alemany, W. Lu, J.M. Tour, Improved synthesis of graphene oxide, ACS Nano 4 (2010) 4806-4814.

[21] S.X. Wu, Q.Y. He, C.M. Zhou, X.Y. Qi, X. Huang, Z.Y. Yin, Y.H. Yang, H. Zhang Synthesis of $\mathrm{Fe}_{3} \mathrm{O}_{4}$ and $\mathrm{Pt}$ nanoparticles on reduced graphene oxide and their use as a recyclable catalyst, Nanoscale 4 (2012) 2478-2483.

[22] R.M. Sellers, Spectrophotometric determination of hydrogen peroxide using potassium titanium(IV) oxalate, Analyst 105 (1980) 950-954.

[23] N.A. Zubir, X.W. Zhang, C. Yacou, J.C.D. da Costa, Fenton-like degradation of acid orange 7 using graphene oxide-iron oxide nanocomposite, Sci. Adv Mater. 6 (2014) 1382-1388.

[24] M. Kruk, M. Jaroniec, Gas adsorption characterization of ordered organic-inorganic nanocomposite materials, Chem. Mater. 13 (2001) 3169-3183.

[25] S. Guo, G.K. Zhang. Y.D. Guo, J.C. Yu, Graphene oxide- $\mathrm{Fe}_{2} \mathrm{O}_{3}$ hybrid material as highly efficient heterogeneous catalyst for degradation of organic contaminants, Carbon 60 (2013) 437-444.

[26] L.Y. Zhang, J. Feng, D.S. Xue, An investigation of thermal decomposition of B-FeOOH nanowire arrays assembled in AAO templates, Mater. Lett. 61 (2007) 1363-1367.

[27] M. Mohapatra, L. Mohapatra, S. Anand, B.K. Mishra, One-pot synthesis of high surface area nano-akaganeite powder and its cation sorption behavior, J. Chem. Eng. Data 55 (2010) 1486-1491.

[28] K. Krishnamoorthy, M. Veerapandian, K. Yun, S.J. Kim, The chemical and structural analysis of graphene oxide with different degrees of oxidation, Carbon 53 (2013) 38-49.

[29] F. Tuinstra, J.L. Koenig, Raman spectrum of graphite, J. Chem. Phys. 53 (1970) 1126-1130.

[30] S. Stankovich, A.A. Dikin, R.D. Piner, K.A. Kohlhass, A. Kleinhammes, Y.Y. Jia, Y. Wu, S. Nguyen, R.S. Ruoff, Synthesis of graphene-based nanosheets via chemical reduction of exfoliated graphite oxide, Carbon 45 (2007) 1558-1565. 
[31] N.A. Zubir, C. Yacou, J. Motuzas, X.W. Zhang, J.C.D. da Costa, Structural and functional investigation of graphene oxide- $\mathrm{Fe}_{3} \mathrm{O}_{4}$ nanocomposites for the heterogeneous Fenton-like reaction, Sci. Rep. 4 (2014) 1-8.

[32] A.P. Chandra, A.R. Gerson, Pyrite (FeS2) oxidation: a sub-micron synchrotron investigation of the initial steps, Geochim. Cosmochim. Acta 75 (2011) 6239-6254.

[33] W.P. Kwan, B.M. Voelker, Rates of hydroxyl radical generation and organic compound oxidation in mineral-catalyzed Fenton-like systems, Environ. Sci. Technol. 37 (2003) 1150-1158.

[34] J.C. Barreiroa, M.D. Capelatoa, L.M. Netob, H.C.B. Hansenc, Oxidative decomposition of atrazine by a Fenton-like reaction in a $\mathrm{H}_{2} \mathrm{O}_{2}$ /ferrihydrite system, Water Res. 41 (2007) 55-62.
[35] W.P. Kwan, B.M. Voelker, Decomposition of hydrogen peroxide and organic compounds in the presence of dissolved iron and ferrihydrite, Environ. Sci. Technol. 36 (2002) 1467-1476.

[36] J.D. Laat, H. Gallard, Catalytic decomposition of hydrogen peroxide by Fe(III) in homogeneous aqueous solution: mechanism and kinetic modeling, Environ. Sci. Technol. 33 (1999) 2726-2732.

[37] W. Luo, L.H. Zhu, N. Wang, H.Q. Tang, M.J. Cao, Y.B. She, Efficient removal of organic pollutants with magnetic nanoscaled $\mathrm{BiFeO}_{3}$ as a reusable heterogeneous Fenton-like catalyst, Environ. Sci. Technol. 44 (2010) $1786-1791$. 